\title{
Menyusun Soal Literasi Saintifik untuk Pembelajaran Biologi Topik Plantae dan Animalia
}

\author{
Adib Rifqi Setiawan ${ }^{1 *}$, Arij Zulfi Mufassaroh ${ }^{2}$ \\ ${ }^{1}$ Madrasah Tasywiquth Thullab Salafiyyah (TBS), Jl. KH. Turaichan Adjhuri no. 23, \\ Kajeksan, Kudus, Jawa Tengah, 59315, Indonesia \\ ${ }^{2}$ Madrasah Annajah Yamra Merauke, Jl.Taman Makam Pahlawan Trikora, Mandala, \\ Kabupaten Merauke, 99614, Indonesia \\ *e-mail: alobatnic@gmail.com
}

\begin{abstract}
Abstrak
Tujuan dari survei lintas bagian ini ialah untuk menemukan keabsahan dan keadanalan tes literasi saintifik untuk pembelajaran biologi di topik plantae dan animalia. Untuk mengungkap keabsahan, diuji berdasarkan penilaian ahli dan keandalan diukur menggunakan konsistensi inernal. Diperoleh bahwa keabsahan dari topik plantae ialah 5 soal sangat layak dan 1 soal cukup layak dengan nilai keandalan sebesar 0,779 serta keabsahan dari topik animalia ialah 4 soal sangat layak dan 2 soal cukup layak dengan nilai keandalan sebesar 0,869. Ini menunjukkan bahwa semua soal dapat digunakan untuk menganalisis kesulitan siswa sebagai bahan merancang rencana pembelajaran biologi berorientasi literasi saintifik di topik plantae dan animalia.
\end{abstract}

Kata Kunci-animalia, literasi saintifik, pembelajaran biologi, plantae, soal

\begin{abstract}
The purpose of this cross-sectional survey work was to find the validity and reliability of scientific literacy's assessment for biological learning in topic plantae and animalia. To reveal validity is assessed based on obtain judgement expert and reliability measured by internal consistency. It was gained that the validity from topic plantae is 5 items very feasible and 1 item quite feasible with reliability's value is 0,779 nor the validity from topic animalia is 4 items very feasible and 2 items quite feasible with reliability's value is 0,869 . It shows that all items can be used to analyzing difficulties of students for designing scientific literacy biological learning oriented's lesson plan in in topic plantae and animalia.
\end{abstract}

Keywords: animalia, assessment, biological learning, scientific literacy, plantae

\section{PENDAHULUAN}

Utari, dkk. (2017) memberi saran bahwa strategi pembelajaran harus ditentukan dibangun dengan baik untuk melatih literasi saintifik, termasuk menjelaskan fenomena alam, membangun dan mengevaluasi percobaan, serta menafsirkan data yang diperoleh dari bukti ilmiah. Saran ini diberikan berdasarkan ulasan deskriptif berdasarkan dimensi Marzano yang dilakukan terhadap pelaksanaan rancangan pembelajaran termodinamika untuk melatih literasi saintifik (Utari, dkk., 2017, hlm. 3-4). Saran tersebut selaras dengan Setiawan (2017) yang mengungkap bahwa per- baikan berkelanjutan perlu dilakukan terhadap rancangan maupun pelaksanaan pembelajaran guna meningkatkan literasi saintifik siswa secara optimal. Ungkapan ini disampaikan atas dasar analisis pelaksanaan penerapan pendekatan saintifik dalam pembelajaran berorientasi literasi saintifik di topik mekanika. Dari keselarasan saran tersebut tampak bahwa keduanya memandang bahwa pembelajaran, terutama fisika yang dijadikan pijakan, perlu diarahkan untuk melatih literasi saintifik.

Literasi saintifik bisa dimaknai sebagai ukuran kemampuan menggunakan pengalaman bela- 
jar untuk memenuhi kebutuhan. Pembelajaran ilmu pengetahuan alam (IPA) selayaknya menjadi saran untuk melatih keterampilan ilmiah serta menumbuhkan kepedulian terhadap alam dan upaya pelestarian fungsinya (Rustaman, 2017, hlm. KS-3). Sehingga dapat dikatakan bahwa tujuan pembelajaran IPA dengan literasi saintifik bisa dipadukan. Dari sini, kami memandang penting dilakukan penyusunan instrumen penilaian literasi saintifik. Rustaman (2017) menyampaikan bahwa pembelajaran IPA berorientas literasi saintifik dapat dilakukan dengan cara mengkaji indikator guna dibekalkan kepada siswa, bukan sekadar membiasakan berlatih soal. Ungkapan yang disampaikan tersebut memang tepat. Karena itu, tujuan penyusunan instrumen ini bukan untuk membiasakan siswa berlatih soal, tetapi sebagai sarana memperoleh profil literasi saintifik siswa.

Berdasarkan uraian tersebut, penelitian ini bertujuan untuk menemukan keabsahan dan keandalan rancangan soal literasi saintifik untuk pembelajaran biologi. Rancangan soal yang disusun berdasarkan indikator domain kompetensi literasi saintifik dari kerangka kerja Programme for International Student Assessment (PISA) 2015. Indikator tersebut dikaitkan dengan topik plantae dan animalia atas dasar pertimbangan agar dapat digunakan dalam pembelajaran di sekolah menengah. Hasil penelitian ini diharapkan memberi bahan untuk memperoleh profil literasi saintifik siswa sebelum dan/atau setelah pembelajaran. Melalui profil sebelum pembelajaran, dapat disusun rancangan pembelajaran berorientasi literasi saintifik yang selaras dengan keadaan siswa. Sementara profil setelah pembelajaran dapat dipakai sebagai bahan evaluasi, baik dari sisi pelaksanaan proses, pencapaian hasil, keefektifan kegiatan, maupun ketiganya. Hasil penelitian ini juga dapat menjadi bahan kajian untuk diperbaiki secara berlanjut supaya lebih operasional ketika diterapkan di lapangan serta kuat dari sisi penelitian. Karena itu, rumusan masalah yang menjadi fokus penelitian ini ialah, "Bagaimana keabsahan dan keandalan rancangan soal literasi saintifik untuk pembelajaran biologi topik plantae dan animalia?"

\section{METODE PENELITIAN}

Tujuan penelitian ini ialah untuk mene-mukan keabsahan dan keandalan rancangan soal literasi saintifik untuk pembelajaran biologi topik plantae dan animalia. Karena itu dibutuhkan data berupa ulasan terhadap soal yang disusun. Berdasarkan tujuan penelitian dan kebutuhan data, metode penelitian yang dapat dipakai ialah pendekatan kuantitatif tipe deskriptif jenis survei dengan desain cross-sectional.

Keabsahan (validity) soal ditentukan berdasarkan validasi ahli (obtain judgement expert), masing-masing terhadap kesesuaian indikator dengan soal, kesesuaian jawaban dengan pertanyaan, serta kesesuaian soal dengan jenjang sekolah (Fraenkel \& Wallen, 2009, hlm. 148). Ahli yang dipilih yaitu akademisi dengan bidang keahlian literasi saintifik (1 orang, selanjutnya Ahli-1) dan evaluasi pembelajaran biologi (1 orang, selanjutnya Ahli-2) serta praktisi pembelajaran biologi sekolah menengah (1 orang, selanjutnya Ahli-3) dan praktisi profesional bidang bahasa (1 orang, selanjutnya Ahli-4). Berikut ini ialah profil setiap ahli tersebut:

Tabel 1.

\begin{tabular}{llll}
\multicolumn{1}{c}{ Tabel 1. } \\
Profil Ahli
\end{tabular}

Hasil validasi berupa komentar yang kemudian diberi skor berdasarkan klasifikasi berikut:

Tabel 2.

Klasifikasi Skor Validasi Ahli

\begin{tabular}{ll}
\hline Skor & Bentuk Komentar \\
\hline 3 & Soal sudah sesuai tanpa perlu mengalami perubahan \\
2 & Soal perlu mengalami perubahan kecil \\
1 & Soal harus mengalami perubahan besar \\
0 & Soal tidak sesuai \\
\hline \hline
\end{tabular}




$$
\begin{aligned}
& \text { yang diolah menggunakan persamaan berikut: } \\
& \qquad \begin{array}{ll}
P(s)=\frac{s}{N} \times & 100 \% \quad \text { (Persamaan 1) } \\
& \text { dengan: } \\
P(b s) & =\text { persentase setiap butir soal } \\
S & =\text { skor setiap butir soal } \\
N & =\text { jumlah keseluruhan butir soal }
\end{array}
\end{aligned}
$$

Hasil dari tabel 2 kemudian ditafsirkan berdasarkan tabel berikut:

Tabel 3.

Penafsiran Penilaian Soal

\begin{tabular}{lll} 
& \multicolumn{2}{c}{ Penafsiran Penilaian Soal } \\
\hline No. & $\begin{array}{l}\text { Rentang Rata-rata Penilaian Ahli } \\
(\%)\end{array}$ & $\begin{array}{l}\text { Kriteria } \\
\text { Instrumen }\end{array}$ \\
\hline 1 & $7,001 \leq \% \leq 10,000$ & Sangat layak \\
2 & $4,001 \leq \% \leq 7,000$ & Cukup layak \\
3 & $0,000 \leq \% \leq 4,000$ & Tidak layak \\
\hline
\end{tabular}

Berdasarkan Tabel 3, instrumen dapat digunakan kalau memenuhi kriteria 'sangat layak' atau 'cukup layak'.

Sementara keandalan (reliability) soal ditentukan berdasarkan internal consistency. Dengan cara ini, dibutuhkan satu kali uji coba yang hasilnya diolah dengan ketentuan instrumen dapat digunakan kalau nilai koefisien keandalan (reliability coefficient) lebih besar dari 0,70 (Fraenkel \& Wallen, 2009, hlm. 157-8). Koefisien keandalan dapat dihitung menggunakan persamaan KuderRichardson Approaches (KR20) berikut (Cronbach, 1951, hlm. 299):

$$
\begin{array}{ll}
\alpha=\frac{n}{n-1} & \left(1-\frac{\sum_{i} V_{i}}{V_{t}}\right) \quad \text { (Persamaan 2) } \\
& \text { dengan: } \\
\alpha & =\text { koefisien alfa } \\
n & =\text { jumlah butir soal } \\
V i & =\text { simpangan baku setiap butir soal } \\
V t & =\text { simpangan baku keseluruhan }
\end{array}
$$

\section{HASIL DAN PMBAHASAN}

Soal literasi saintifik yang digunakan dalam

\begin{tabular}{|c|c|}
\hline Kompetensi & Indikator \\
\hline ilmiah & $\begin{array}{ll}\text { Mengidentifikasi, menggunakan, } & \text { serta } \\
\text { menghasilkan model dan representasi yang } & \\
\text { jelas. } & \\
\text { Menjelaskan implikasi potensial } & \text { dari } \\
\text { pengetahuan ilmiah bagi masyarakat. } & \end{array}$ \\
\hline $\begin{array}{l}\text { Merancang dan } \\
\text { mengevaluasi } \\
\text { penyelidikan } \\
\text { ilmiah }\end{array}$ & $\begin{array}{l}\text { Mengusulkan cara mengeksplorasi secara } \\
\text { ilmiah terhadap pertanyaan yang diberikan. } \\
\text { Mengevaluasi cara mengeksplorasi secara } \\
\text { ilmiah pertanyaan yang diberikan. } \\
\text { Mendeskripsikan dan mengevaluasi berbagai } \\
\text { cara yang digunakan oleh ilmuan untuk } \\
\text { menentukan keabsahan dan keobjektifan data } \\
\text { serta keumuman penjelasan. }\end{array}$ \\
\hline $\begin{array}{l}\text { Menafsirkan data } \\
\text { dan bukti secara } \\
\text { ilmiah }\end{array}$ & $\begin{array}{l}\text { Mengubah data dari satu representasi ke } \\
\text { representasi yang lain. } \\
\text { Menganalisis dan menafsirkan data dan } \\
\text { menarik kesimpulan yang tepat. }\end{array}$ \\
\hline
\end{tabular}
penelitian ini berjumlah 14 butir untuk topik plantae dan 20 butir untuk topik animalia. Literasi saintifik dalam penelitian ini dibatasi di domain kompetensi, meliputi: menjelaskan fenomena secara ilmiah $\left(\mathrm{K}_{1}\right)$, merancang dan mengevaluasi penyelidikan ilmiah $\left(\mathrm{K}_{2}\right)$, dan menafsirkan data dan bukti secara ilmiah $\left(\mathrm{K}_{3}\right)$. Rincian indikator tersebut dapat dilihat melalui tabel berikut:

Tabel 4.

\begin{tabular}{lll}
\multicolumn{4}{c}{ Indikator Kompetensi Literasi Saintifik } \\
\hline Kompetensi & Indikator & \\
\hline Menjelaskan & Mengingat dan menerapkan & pengetahuan \\
fenomena secara & ilmiah yang sesuai.
\end{tabular}

Indikator tersebut digunakan sebagai acuan dalam menyusun soal dengan konten terkait topik plantae dan animalia. Pilihan mengaitkan dengan topik tertentu dilakukan karena kami berupaya agar keseluruhan pembelajaran biologi diarahkan untuk melatih literasi saintifik. Sehingga diperlukan soal sebagai alat ukur literasi saintifik dari beragam topik pembelajaran biologi. Dengan beragam soal tersebut, guru dan/atau peneliti dapat melakukan pengukuran literasi saintifik secara berlanjut, seperti menggunakan desain time series, tidak hanya mengukur dari satu topik saja, misalnya menggunakan desain one shot case stu$d y$, untuk memperoleh keabsahaan dan keandalan hasil yang lebih tinggi. Selain itu, keragaman topik juga lebih memudahkan guru untuk menunjukkan kepada siswa kaitan antara pengalaman terlibat pembelajaran dengan keterampilan yang ditargetkan dapat dimiliki.

Soal disusun dalam bentuk uraian. Pilihan ini diambil karena kami memandang bahwa tes tipe uraian memiliki keunggulan untuk mengukur kemampuan individu dalam mengorganisasikan, mengintregasikan, menganalisis, menyintesiskan, dan mengevaluasi informasi. Karena itu, soal bentuk uraian dipandang lebih cocok untuk digunakan. Banyak soal yang disusun ialah 6 kelompok untuk setiap topik plantea dan animalia. Kami menyadari bahwa untuk soal tipe ini, terdapat kesulitan dalam hal melakukan penyekoran. Sehingga kami membuat rancangan sederhana guna mengklasifikasikan skor dari setiap jawaban, yang ditampilkan melalui tabel berikut: 
Tabel 5.

Klasifikasi Skor Setiap Jawaban

\begin{tabular}{|c|c|}
\hline Skor & Bentuk Jawaban \\
\hline 2 & Sama seperti yang diharapkan \\
\hline 2 & $\begin{array}{l}\text { Hampir seperti yang diharapkan tanpa terdapat } \\
\text { pernyataan yang salah }\end{array}$ \\
\hline 1 & $\begin{array}{l}\text { Mengandung hal yang benar dan terdapat pula pernyataan } \\
\text { yang salah }\end{array}$ \\
\hline 0 & $\begin{array}{l}\text { Jawaban tidak berhubungan dengan pertanyaan yang } \\
\text { diajukan }\end{array}$ \\
\hline 0 & Tidak menjawab \\
\hline \multicolumn{2}{|c|}{$\begin{array}{l}\text { yang kemudian dijumlah secara keseluruhan menggunakan } \\
\text { persamaan berikut: }\end{array}$} \\
\hline & $\begin{array}{l}S=\sum R \\
\text { dengan: }\end{array}$ \\
\hline & $=$ skor setiap siswa \\
\hline & $=$ jawaban setiap butir soal \\
\hline
\end{tabular}

Langkah yang dilakukan dalam penyusunan soal sebagai berikut:

(a). Membuat matrikulasi domain kompetensi dan indikator soal;

(b). Menyusun soal berdasarkan matrikulasi;

(c). Meminta validasi ahli;

(d). Menganalisis hasil validasi ahli (analisis keabsahan);

(e). Meminta siswa mengerjakan soal (mengujicobakan); serta

(f). Menganalisis hasil ujicoba (analisis keandalan).

Contoh soal yang disusun sebagai berikut:

Tabel 6.

Contoh Soal yang Disusun

\begin{tabular}{ll}
\hline Indikator & $\begin{array}{l}\text { Mengidentifikasi, menggunakan, serta menghasilkan } \\
\text { model dan representasi yang jelas }\end{array}$ \\
Konten & $\begin{array}{l}\text { Hewan tak bertulang belakang (Invertebrata) } \\
\text { Soal }\end{array}$ \\
& $\begin{array}{l}\text { Dilihat dari lapisan nutfah, cacing tanah (Lumbricus } \\
\text { terrestris) memiliki kekhasan berupa tubuh dilapisi } \\
\text { oleh ektoderm dan saluran pencernaan dilapisi oleh } \\
\text { endoderm. Di antara ektoderm dan endoderm, } \\
\text { terdapat rongga tubuh dan dilapisi oleh jaringan } \\
\text { yang berasal dari mesoderm. }\end{array}$ \\
Pertanyaan & $\begin{array}{l}\text { Bagaimana ilustrasi ciri-ciri Cacing tanah tersebut? } \\
\text { Jawaban } \\
\text { Ilustrasi ciri-ciri Caving tanah tersebut seperti } \\
\text { berikut: }\end{array}$ \\
&
\end{tabular}

Setelah dilakukan validasi kepada 4 ahli, diperoleh komentar yang beragam. Namun, secara umum soal sudah sesuai tanpa perlu banyak peru- bahan. Setiap soal yang sudah tidak dibahas di sini, karena dianggap tidak terlampau perlu. Secara khusus, beberapa komentar yang kami tanggapi dalam bentuk memperbaiki soal diuraikan dalam bentuk deskripsi berikut:

Untuk soal kelompok T-1 topik plantae, Ahli1 menyebut bahwa soal sudah tepat kalau untuk mengingat pengetahuan ilmiah yang sesuai, tapi belum tepat untuk indikator menerapkan pengetahuan ilmiah yang sesuai. Ahli-2 menyebut bahwa sebaiknya pertanyaan lebih rinci seperti, "Berdasarkan bagan di atas, berilah penjelasan dengan melengkapi tabel berikut, sehingga jelas hubungan antar konsep yang disajikan dalam bagan!" serta untuk jawaban bentuk tubuh diganti dengan struktur tubuh. Ahli-3 menyebut bahwa soal perlu disempurnakan, seperti pernyataan ditambah data umum dasar klasifikasi tumbuhan. Sementara Ahli-4 menyebut bahwa perlu disempurnakan, seperti bentuk tubuh menjadi struktur tubuh. Tanggapan kami terhadap komentar 4 ahli tersebut ialah menyesuaiakn soal dengan indikator menerapkan pengetahuan ilmiah yang sesuai. Sehingga soal diubah dalam bentuk penyajian data untuk menerapkan pengetahuan ilmiah, yaitu, "Jisoo menemukan suatu tumbuhan di pekarangan rumah dengan ciri berdaun lebar, pertulangan menyirip, tingginya 10 meter $\mathrm{cm}$, serta mahkota bunga kelipatan lima. Berdasarkan ciri tersebut, bagaimana klasifikasi tumbuhan yang ditemukan oleh Jisoo?"

Untuk soal kelompok T-2 topik plantae, Ahli2 menyebut bahwa pertanyaan sebaiknya, "Apakah rancangan pecobaan Rosé tersebut apakah sudah tepat? Mengapa demikian?" Sementara Ahli-4 menyebut bahwa pertanyaan perlu disempurnakan, seperti: Rosé ingin mengerti sebaiknya diubah menjadi Rosé ingin menganalisis. Tanggapan kami terhadap komentar 2 ahli tersebut ialah melakukan perubahan kecil terhadap soal tanpa mengubah uraian yang telah disusun.

Untuk soal kelompok T-3 topik plantae Ahli-4 menyebut bahwa pertanyaan sebaiknya disempurnakan bahasanya. Tanggapan kami terhadap komentar 1 ahli tersebut ialah melengkapi pertanyaan dengan kalimat berikut, "Berdasarkan gambar tersebut, bagaimana penjelasan model tumbuhan lumut dalam bentuk tabel berikut?" 
Untuk soal kelompok T-4 topik plantae, Ahli2 dan Ahli-4 sama-sama menyebut bahwa bahasa pertanyaan perlu disempurnakan. Tanggapan kami terhadap komentar 2 ahli tersebut ialah mengubah pertanyaan menjadi, "Berdasarkan alur pergiliran keturunan tumbuhan paku tersebut, bagaimana pergiliran tumbuhan paku dalam bentuk bagan beserta keterangan setiap fasenya?"

Untuk soal kelompok T-5 topik plantae, Ahli4 menyebut bahwa bahasa perlu disempurnakan agar tidak menimbulkan multi tafsir kepada siswa. Tanggapan kami terhadap komentar 1 ahli tersebut ialah mengubah pertanyaan menjadi, "Dari kelompok apa tumbuhan yang diamati oleh Jisoo tersebut?"

Untuk soal kelompok T-6 topik plantae, Ahli1 menyebut bahwa sebaiknya pertanyaan perlu diganti dengan menampilkan data dalam bentuk tabel atau grafik sehingga siswa bisa menafsirkan data tersebut untuk menarik kesimpulan. Tanggapan kami terhadap komentar 1 ahli tersebut ialah tidak melakukan perubahan terhadap soal. Hal ini karena kami memandang narasi soal sudah tepat sesuai dengan indikator tanpa harus menampilkan data dalam bentuk tabel atau grafik.

Untuk soal kelompok H-1 topik animalia, Ahli-4 menyebut bahwa bahasa perlu disempurnakan. Tanggapan kami terhadap komentar 1 ahli tersebut ialah mengubah pertanyaan menjadi, "Berdasarkan ilustrasi bagan pengelompokkan hewan tersebut, bagaimana penjelasan kalian melalui tabel berikut?"

Untuk soal kelompok H-2 topik animalia, Ahli-2 menyebut bahwa pertanyaan perlu disempurnakan. Sementara Ahli-4 menyebut bahwa bahasa perlu disempurnakan. Tanggapan kami terhadap komentar 2 ahli tersebut ialah menyempurnakan penggunaan bahasa menjadi, "Untuk dapat menjawab tujuan penelitian Jennie tersebut, bagaimana bentuk tabel pengamatan yang harus dibuat secara tepat, jelas, dan lengkap dengan keterangan tindakannya?

Untuk soal kelompok $\mathrm{H}-4$ topik animalia, Ahli-2 menyebut bahwa soal sebaiknya menampilkan data berupa tabel atau grafik, sehingga siswa ditutut bisa mengubah representasi. Ahli-3 menyebut bahwa soal dan tingkatan diselerasakan lagi. Sementara Ahli-4 menyebut bahwa bahasa disempurnakan lagi. Tanggapan kami terhadap komentar 4 ahli tersebut ialah mengubah pertanyaan menjadi, "Dari ilustrasi tersebut, bagaimana penjelasan simetri tubuh Ubur-ubur laut pasifik dalam bentuk tabel?" serta, "Berdasarkan tabel simetri tubuh yang tepat, Ubur-ubur laut pasifik termasuk kelompok simetri tubuh apa?"

Untuk soal kelompok H-5 topik animalia, Ahli-1 menyebut bahwa soal dan indikator kurang sesuai. Ahli-2 menyebut bahwa soal sebaiknya menampilkan kasus, sehingga siswa ditutut dapat mengevaluasi. Ahli-3 menyebut bahwa soal dan tingkatan diselerasakan lagi. Sementara Ahli4 menyebut bahwa bahasa disempurnakan lagi. Tanggapan kami terhadap komentar 4 ahli tersebut ialah mengubah soal menjadi, "Berdasarkan tabel tersebut, apakah Lalisa dapat membuat penjelasan umum mengenai hewan bertulang belakang? Mengapa demikian?"

Untuk soal kelompok H-6 topik animalia, Ahli-2 menyebut bahwa pertanyaan perlu disempurnakan. Sementara Ahli-4 menyebut bahwa bahasa perlu disempurnakan. Tanggapan kami terhadap komentar 2 ahli tersebut ialah mengubah pertanyaan menjadi, "Berdasarkan reaksi kimia tersebut, apa manfaat hasil dari proses metabolisme di tubuh Rosé bagi kehidupan dalam ekosistem?"

Berdasarkan keseluruhan komentar tersebut, dilakukan klasifikasi setiap soal berikut:

Tabel 7.

Hasil Validasi Ahli

\begin{tabular}{ccccccc}
\hline Soal & \multicolumn{4}{c}{ Skor dari Ahli } & $\begin{array}{c}\text { Jumlah } \\
\text { Skor }\end{array}$ & Kriteria Soal \\
\cline { 2 - 5 } & $\mathbf{1}$ & $\mathbf{2}$ & $\mathbf{3}$ & $\mathbf{4}$ & & \\
\hline T-1 & 1 & 2 & 2 & 2 & 58 & Cukup Layak \\
T-2 & 3 & 2 & 3 & 2 & 83 & Sangat Layak \\
T-3 & 3 & 3 & 3 & 2 & 92 & Sangat Layak \\
T-4 & 3 & 2 & 3 & 2 & 83 & Sangat Layak \\
T-5 & 3 & 3 & 3 & 2 & 92 & Sangat Layak \\
T-6 & 1 & 3 & 3 & 3 & 83 & Sangat Layak \\
A-1 & 3 & 3 & 3 & 2 & 92 & Sangat Layak \\
A-2 & 3 & 2 & 3 & 2 & 83 & Sangat Layak \\
A-3 & 3 & 3 & 3 & 3 & 100 & Sangat Layak \\
A-4 & 3 & 2 & 2 & 2 & 75 & Sangat Layak \\
A-5 & 1 & 1 & 1 & 2 & 42 & Cukup Layak \\
A-6 & 3 & 1 & 3 & 1 & 67 & Cukup Layak \\
\hline
\end{tabular}


Setelah melakukan perbaikan berdasarkan komentar keempat ahli, kami melakukan ujicoba soal. Hasil uji coba dijadikan sebagai acuan untuk menemukan nilai koefisien keandalan soal. Melalui uji coba juga bisa didapatkan informasi banyak waktu yang diperlukan siswa untuk menjawab soal. Setelah dilakukan uji coba soal, diperoleh hasil sebagai berikut:

Tabel 8 Hasil Uji Coba Soal Plantae

\begin{tabular}{|c|c|c|c|c|c|c|c|c|c|c|c|c|c|c|}
\hline \multirow{2}{*}{$\begin{array}{l}\text { Sis } \\
\text { wa }\end{array}$} & \multicolumn{2}{|c|}{ P1 } & \multicolumn{3}{|c|}{ P2 } & $\mathbf{P}$ & $\begin{array}{l}P \\
4\end{array}$ & \multicolumn{2}{|c|}{ P5 } & \multicolumn{5}{|c|}{ P6 } \\
\hline & 1 & 2 & 3 & 4 & 5 & 6 & 7 & 8 & 9 & $\begin{array}{l}1 \\
0\end{array}$ & $\begin{array}{l}1 \\
1\end{array}$ & $\begin{array}{l}1 \\
2\end{array}$ & $\begin{array}{l}1 \\
3\end{array}$ & $\begin{array}{l}1 \\
4\end{array}$ \\
\hline
\end{tabular}

\footnotetext{
$\begin{array}{lllllllllllllll}1 & 2 & 2 & 1 & 2 & 2 & 1 & 0 & 2 & 2 & 2 & 1 & 0 & 1 & 2\end{array}$

$\begin{array}{lllllllllllllll}2 & 1 & 2 & 1 & 2 & 2 & 2 & 2 & 2 & 2 & 2 & 2 & 2 & 1 & 2\end{array}$

$\begin{array}{lllllllllllllll}3 & 1 & 2 & 1 & 2 & 2 & 2 & 2 & 2 & 2 & 2 & 2 & 2 & 1 & 2\end{array}$

$\begin{array}{lllllllllllllll}4 & 1 & 2 & 1 & 2 & 2 & 2 & 1 & 2 & 2 & 2 & 2 & 0 & 1 & 2\end{array}$

$\begin{array}{lllllllllllllll}5 & 1 & 2 & 1 & 2 & 2 & 2 & 2 & 2 & 2 & 1 & 2 & 0 & 1 & 0\end{array}$

$\begin{array}{lllllllllllllll}6 & 1 & 0 & 1 & 1 & 1 & 0 & 2 & 0 & 0 & 0 & 2 & 2 & 1 & 2\end{array}$

$\begin{array}{lllllllllllllll}7 & 2 & 2 & 0 & 2 & 2 & 0 & 0 & 1 & 1 & 2 & 2 & 2 & 1 & 2\end{array}$

$\begin{array}{lllllllllllllll}8 & 2 & 2 & 1 & 2 & 2 & 1 & 1 & 1 & 1 & 2 & 2 & 2 & 1 & 2\end{array}$

$\begin{array}{lllllllllllllll}9 & 2 & 2 & 1 & 2 & 2 & 2 & 1 & 1 & 1 & 2 & 2 & 2 & 1 & 2\end{array}$

$\begin{array}{lllllllllllllll}10 & 2 & 2 & 1 & 2 & 2 & 0 & 2 & 2 & 2 & 2 & 2 & 2 & 1 & 2\end{array}$

$\begin{array}{lllllllllllllll}11 & 2 & 2 & 1 & 2 & 2 & 0 & 2 & 2 & 2 & 2 & 2 & 2 & 1 & 2\end{array}$

$\begin{array}{lllllllllllllll}12 & 2 & 2 & 1 & 2 & 2 & 2 & 2 & 2 & 2 & 0 & 2 & 2 & 1 & 2\end{array}$

$\begin{array}{lllllllllllllll}13 & 0 & 2 & 2 & 1 & 2 & 2 & 2 & 2 & 2 & 2 & 2 & 2 & 1 & 2\end{array}$

$\begin{array}{lllllllllllllll}14 & 2 & 2 & 2 & 1 & 2 & 2 & 2 & 2 & 2 & 0 & 2 & 2 & 0 & 2\end{array}$

$\begin{array}{lllllllllllllll}15 & 0 & 2 & 2 & 0 & 2 & 2 & 0 & 1 & 1 & 0 & 2 & 2 & 1 & 2\end{array}$

$\begin{array}{lllllllllllllll}16 & 0 & 2 & 2 & 1 & 2 & 2 & 2 & 2 & 2 & 2 & 2 & 2 & 1 & 2\end{array}$

$\begin{array}{lllllllllllllll}17 & 2 & 2 & 2 & 1 & 2 & 2 & 2 & 1 & 1 & 2 & 1 & 0 & 1 & 2\end{array}$

$\begin{array}{lllllllllllllll}18 & 2 & 1 & 0 & 1 & 2 & 2 & 2 & 1 & 1 & 2 & 2 & 0 & 1 & 2\end{array}$

$\begin{array}{lllllllllllllll}19 & 2 & 2 & 0 & 1 & 2 & 2 & 2 & 1 & 1 & 2 & 2 & 2 & 1 & 2\end{array}$

$\begin{array}{lllllllllllllll}20 & 2 & 2 & 2 & 1 & 2 & 2 & 2 & 1 & 1 & 2 & 1 & 2 & 1 & 2\end{array}$

$\begin{array}{lllllllllllllll}21 & 2 & 1 & 2 & 1 & 2 & 2 & 0 & 1 & 1 & 2 & 2 & 2 & 1 & 2\end{array}$

$\begin{array}{lllllllllllllll}22 & 2 & 2 & 2 & 1 & 2 & 2 & 2 & 2 & 2 & 2 & 2 & 2 & 1 & 2\end{array}$

$\begin{array}{lllllllllllllll}23 & 2 & 2 & 2 & 1 & 2 & 2 & 2 & 2 & 2 & 2 & 2 & 0 & 0 & 1\end{array}$

$\begin{array}{lllllllllllllll}24 & 2 & 2 & 0 & 0 & 1 & 2 & 2 & 1 & 1 & 2 & 0 & 0 & 1 & 1\end{array}$

$\begin{array}{lllllllllllllll}25 & 2 & 0 & 0 & 1 & 1 & 0 & 0 & 0 & 0 & 2 & 2 & 0 & 1 & 0\end{array}$

$\begin{array}{lllllllllllllll}26 & 2 & 2 & 0 & 1 & 0 & 2 & 0 & 0 & 0 & 2 & 2 & 2 & 1 & 1\end{array}$

$\begin{array}{llllllllllllllll}27 & 2 & 2 & 2 & 1 & 1 & 2 & 2 & 2 & 2 & 2 & 2 & 2 & 1 & 2\end{array}$

$\begin{array}{lllllllllllllll}28 & 2 & 2 & 2 & 1 & 2 & 2 & 2 & 2 & 2 & 2 & 2 & 0 & 1 & 2\end{array}$

$\begin{array}{llllllllllllllll}29 & 2 & 2 & 0 & 1 & 2 & 0 & 1 & 2 & 2 & 2 & 2 & 2 & 1 & 2\end{array}$
}

\begin{tabular}{|c|c|c|c|c|c|c|c|c|c|c|c|c|c|c|}
\hline \multirow{2}{*}{$\begin{array}{l}\text { Sis } \\
\text { wa }\end{array}$} & \multicolumn{2}{|c|}{ P1 } & \multicolumn{3}{|c|}{ P2 } & \multirow{2}{*}{$\begin{array}{l}\mathbf{P} \\
3 \\
6\end{array}$} & \multirow{2}{*}{$\begin{array}{l}P \\
4 \\
7\end{array}$} & \multicolumn{2}{|c|}{ P5 } & \multicolumn{5}{|c|}{ P6 } \\
\hline & 1 & 2 & 3 & 4 & 5 & & & 0 & 9 & $\begin{array}{l}\mathbf{1} \\
\mathbf{0}\end{array}$ & $\begin{array}{l}1 \\
1\end{array}$ & $\begin{array}{l}1 \\
2\end{array}$ & 1 & $\begin{array}{l}1 \\
4\end{array}$ \\
\hline 30 & 1 & 2 & 1 & 1 & 1 & 0 & 1 & 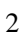 & 2 & 1 & 0 & 0 & 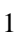 & 1 \\
\hline 31 & 2 & 2 & 1 & 2 & 2 & 2 & 1 & & 1 & 2 & 1 & 2 & 1 & 2 \\
\hline 32 & 1 & 1 & 1 & 1 & 0 & 0 & 1 & 0 & 0 & 0 & 1 & 2 & 1 & 2 \\
\hline 33 & 2 & 2 & 1 & 2 & 2 & 0 & 1 & & 1 & 0 & 2 & 1 & 1 & 2 \\
\hline 34 & 1 & 2 & 1 & 2 & 2 & 2 & 1 & 2 & 2 & 2 & 2 & 2 & 1 & 2 \\
\hline 35 & 2 & 2 & 1 & 2 & 2 & 0 & 1 & 2 & 2 & 2 & 2 & 2 & 1 & 2 \\
\hline 36 & 2 & 2 & 1 & 2 & 0 & 0 & 1 & & 1 & 0 & 2 & 2 & 1 & 2 \\
\hline 37 & 2 & 2 & 1 & 2 & 2 & 0 & 1 & & 2 & 2 & 2 & 1 & 1 & 2 \\
\hline 38 & 2 & 2 & 1 & 2 & 2 & 0 & 1 & & 2 & 2 & 2 & 1 & 1 & 2 \\
\hline 39 & 2 & 2 & 1 & 2 & 2 & 0 & 1 & & 2 & 0 & 2 & 2 & I & 1 \\
\hline 40 & 1 & 2 & 1 & 2 & 2 & 0 & 1 & 2 & 2 & 2 & 1 & 0 & 1 & 1 \\
\hline
\end{tabular}

Tabel 8 kemudian diolah menggunakan persamaan 2, yang diperoleh nilai koefisien alfa sebesar 0,779. Artinya soal plantae dapat digunakan.

Tabel 9.

Hasil Uji Coba Soal Animalia

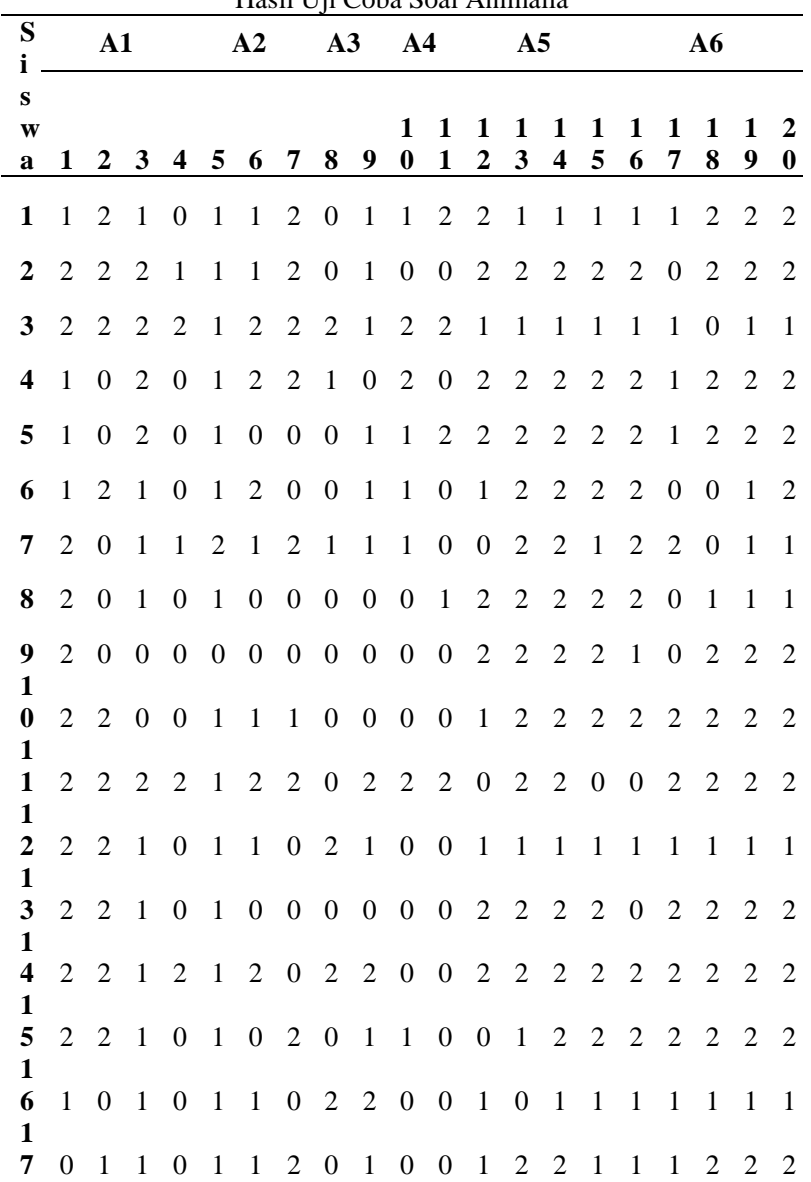




\begin{tabular}{|c|c|c|c|c|c|c|c|c|c|c|c|c|c|c|c|c|c|c|c|c|}
\hline 5 & & A & & & & 12 & & & & A & & & $\mathbf{A}$ & & & & & A6 & & \\
\hline $\begin{array}{l}\mathbf{w} \\
\mathbf{a}\end{array}$ & 1 & 2 & 3 & 4 & 5 & 6 & 7 & 8 & 9 & $\begin{array}{l}\mathbf{1} \\
\mathbf{0}\end{array}$ & & $\begin{array}{l}1 \\
2\end{array}$ & $\begin{array}{l}\mathbf{1} \\
\mathbf{3}\end{array}$ & $\begin{array}{l}1 \\
4\end{array}$ & $\begin{array}{l}1 \\
5\end{array}$ & $\begin{array}{l}1 \\
6\end{array}$ & $\begin{array}{l}1 \\
7\end{array}$ & $\begin{array}{l}1 \\
8\end{array}$ & $\begin{array}{l}1 \\
9\end{array}$ & $\begin{array}{l}\mathbf{2} \\
\mathbf{0}\end{array}$ \\
\hline 1 & & & & & & & & & & & & & & & & & & & & \\
\hline 1 & 1 & 1 & 2 & 2 & 1 & 1 & 2 & 2 & 1 & 1 & 0 & 2 & 2 & 2 & 0 & 0 & 2 & 0 & & 0 \\
\hline $\begin{array}{l}9 \\
2\end{array}$ & 2 & 2 & 1 & 1 & 1 & 1 & 2 & 2 & 1 & 1 & 2 & 1 & 2 & 2 & 2 & 2 & 1 & 1 & 1 & 0 \\
\hline $\begin{array}{l}0 \\
2\end{array}$ & 2 & 2 & 1 & 2 & 1 & 1 & 2 & 2 & 1 & 1 & 2 & 0 & 1 & 2 & 0 & 0 & 0 & 1 & 0 & 0 \\
\hline $\begin{array}{l}1 \\
2\end{array}$ & 1 & 2 & 2 & 2 & 1 & 1 & 2 & 2 & 1 & 1 & 2 & 1 & 1 & 1 & 1 & 1 & 1 & 2 & 1 & 0 \\
\hline $\begin{array}{l}2 \\
2\end{array}$ & 1 & 2 & 2 & 2 & 1 & 1 & 2 & 1 & 1 & 1 & 2 & 1 & 1 & 2 & 2 & 0 & 2 & 1 & 0 & 0 \\
\hline $\begin{array}{l}3 \\
2\end{array}$ & 2 & 2 & 1 & 0 & 1 & 0 & 0 & 0 & 1 & 1 & 0 & 2 & 2 & 2 & 2 & 0 & 0 & 2 & 0 & 0 \\
\hline $\begin{array}{l}4 \\
2\end{array}$ & 0 & 0 & 1 & 0 & 0 & 0 & 0 & 0 & 0 & 0 & 0 & 0 & 0 & 2 & 1 & 0 & 0 & 1 & 0 & 0 \\
\hline $\begin{array}{l}5 \\
2\end{array}$ & 0 & 0 & 2 & 2 & 1 & 1 & 2 & 2 & 1 & 2 & 2 & 1 & 1 & 1 & 0 & 1 & 1 & 1 & 0 & 0 \\
\hline $\begin{array}{l}6 \\
2\end{array}$ & 1 & 0 & 1 & 2 & 1 & 1 & 2 & 2 & 1 & 2 & 2 & 1 & 0 & 2 & 2 & 1 & 1 & 1 & 0 & 0 \\
\hline $\begin{array}{l}7 \\
2\end{array}$ & 1 & 2 & 2 & 2 & 1 & 1 & 0 & 2 & 1 & 0 & 0 & 2 & 0 & 2 & 0 & 2 & 0 & 0 & 1 & 0 \\
\hline 8 & 2 & 0 & 2 & 2 & 1 & 1 & 2 & 2 & 1 & 1 & 2 & 2 & 2 & 1 & 2 & 2 & 0 & 1 & 2 & 2 \\
\hline $\begin{array}{l}9 \\
3\end{array}$ & 2 & 2 & 2 & 2 & 1 & 1 & 2 & 2 & 1 & 2 & 2 & 2 & 2 & 1 & 2 & 2 & 0 & 1 & 2 & 0 \\
\hline $\begin{array}{l}\mathbf{0} \\
\mathbf{3}\end{array}$ & 0 & 0 & 2 & 2 & 1 & 1 & 2 & 2 & 1 & 1 & 2 & 1 & 2 & 1 & 2 & 2 & 0 & 1 & 2 & 2 \\
\hline $\begin{array}{l}1 \\
3\end{array}$ & 2 & 1 & 2 & 2 & 1 & 1 & 2 & 2 & 1 & 2 & 2 & 2 & 1 & 2 & 2 & 2 & 2 & 2 & 2 & 1 \\
\hline $\begin{array}{l}2 \\
3\end{array}$ & 2 & 2 & 2 & 2 & 1 & 1 & 2 & 2 & 1 & 2 & 2 & 2 & 1 & 2 & 2 & 2 & 1 & 1 & 0 & 1 \\
\hline $\begin{array}{l}3 \\
3\end{array}$ & 2 & 2 & 2 & 2 & 1 & 1 & 2 & 2 & 1 & 1 & 2 & 0 & 1 & 2 & 2 & 2 & 1 & 0 & 1 & 1 \\
\hline $\begin{array}{l}4 \\
3\end{array}$ & 2 & 2 & 2 & 2 & 1 & 1 & 2 & 2 & 1 & 2 & 1 & 0 & 1 & 2 & 2 & 2 & 1 & 1 & 1 & 2 \\
\hline $\begin{array}{l}5 \\
3\end{array}$ & 2 & 0 & 2 & 2 & 1 & 1 & 2 & 2 & 1 & 2 & 1 & 2 & 1 & 2 & 2 & 2 & 1 & 2 & 2 & 1 \\
\hline $\begin{array}{l}6 \\
3\end{array}$ & 2 & 2 & 2 & 2 & 1 & 1 & 2 & 2 & 1 & 2 & 0 & 2 & 1 & 2 & 2 & 0 & 1 & 2 & 2 & 1 \\
\hline $\begin{array}{l}7 \\
3\end{array}$ & 2 & 2 & 2 & 2 & 1 & 2 & 2 & 1 & 0 & 2 & 2 & 2 & 1 & 2 & 2 & 2 & 2 & 1 & 2 & 2 \\
\hline $\begin{array}{l}8 \\
3\end{array}$ & 2 & 2 & 1 & 2 & 1 & 2 & 2 & 2 & 2 & 2 & 2 & 2 & 1 & 2 & 2 & 2 & 2 & 1 & 2 & 2 \\
\hline 9 & 2 & 1 & 1 & 2 & 1 & 2 & 2 & 2 & & 2 & 2 & 0 & 0 & 1 & 2 & 2 & 1 & 2 & 2 & 1 \\
\hline 0 & 1 & 2 & 1 & 2 & 1 & 2 & 2 & 2 & 1 & 2 & 2 & 0 & 1 & 1 & 0 & 0 & 0 & 0 & 0 & \\
\hline
\end{tabular}

Tabel 9 kemudian diolah menggunakan persamaan 2, yang diperoleh nilai koefisien alfa sebesar 0,869 . Artinya soal plantae dapat digunakan. Dapat dilihat bahwa terdapat perbedaan nilai koefisien alfa untuk topik plantae dan animalia, yang memiliki perbedaan sebesar 0,090 . Untuk skala 1,000 , rentang perbedaan tersebut dapat dianggap tidak menyolok. Ketika kami menghitung nilai koefisien alfa gabungan antara topik plantae dan animalia, diperoleh hasil sebesar 0,855 . Hasil keseluruhan ini lebih besar 0,076 daripada khusus topik plantae, tapi lebih kecil 0,014 ketimbang topik animalia saja. Walau begitu, secara keseluruhan tidak ditemukan perbedaan menyolok, baik khusus topik plantae, topik animalia saja, maupun keduanya. Selain itu, keseluruhan pengolahan menunjukkan bahwa soal termasuk dalam kategori dapat digunakan.

\section{KESIMPULAN}

Berdasarkan penelitian yang telah dilakukan, soal yang disusun dapat dijadikan sebagai alat ukur literasi saintifik siswa dalam pembelajaran biologi topik plantae dan animali di sekolah menengah. Secara rinci, hasil validasi ahli memberi kesimpulan bahwa terdapat 5 soal kategori 'sangat layak' dan 1 soal kategori 'cukup layak' untuk topik plantae serta 4 soal kategori 'sangat layak' dan 2 soal kategori 'cukup layak' untuk topik plantae. Sementara berdasarkan hasil ujicoba, diperoleh nilai koefisien alfa masing-masing sebesar 0,779 untuk topik plantae, 0,869 untuk topik animalia, serta 0,855 untuk gabungan keduanya.

\section{DAFTAR PUSTAKA}

Cronbach, Lee J. (1951). Coefficient alpha and the internal structure of tests. Psychometrika, 16: 297-334.

Fraenkel, Jack R. \& Wallen, Norman E. (2009). How to design and evaluate research in education (7th ed.). New York. McGrawHill Companies.

OECD. (2013). Pisa 2015 draft science framework march 2013. Paris: OECD.

Rustaman, Nuryani Y. (2017). Mewujudkan sistem pembelajaran sains/biologi berorientasi pengembangan literasi peserta didik. Dalam Prosiding Seminar Nasional III Tahun 2017 "Biologi, Pembelajaran, dan Lingkungan Hidup Perspektif Interdisipliner”: KS.

Setiawan, Adib Rifqi. (2017). Penerapan pendekatan saintifik untuk melatihkan literasi saintifik dalam domain kompetensi pada topik gerak lurus di sekolah menengah pertama. Skripsi Universitas Pendidikan Indonesia. 
Utari, Setiya, dkk. (2017). Recostructing the physics teaching didactic based on marzano's learning dimension on training the scientific literacies. Journal of Physics: Conference Series, 812(1): 012102.

Penulisan buku dengan editor disertai (Ed.) untuk satu editor dan (Eds.) untuk lebih dari satu editor. Contohnya:

Maher, B. A. (Ed.). (1964-1972). Progress in experimental personality research (6 vols.). New York: Academic Press.

Duncombe, J.U. (1959). Infrared navigationPart I: An assessment of feasibility (Periodical style). IEEE Trans. Electron Devices, 11(5), 34-39.

Chen, S., Mulgrew, B., and Grant, P.M. (1989). A clustering technique for digital communications channel equalization using radial basis function networks. IEEE Trans. Neural Networks, 4, 570-578.

Lucky, R.W. (1965). "Automatic equalization for digital communication," Bell Syst. Tech. J., 44(4), 547-588.
Fang, Q., Zhao, F., \& Guibas, L. (2003). Lightweight sensing and communication protocols for target enumeration and aggregation. In M. Gerla, A. Ephremides, \& M. Srivastava (Eds.), MobiHoc '03 fourth ACM symposium on mobile ad hoc networking and computing (pp. 165-176). New York, NY: ACM Press.

Banks, I. (n.d.). The NHS Direct healthcare guide. Retrieved from http://www.health careguide.nhsdirect.nhs.uk

Alexander, J., \& Tate, M. A. (2001). Evaluating web resources. Retrieved from Widener University, Wolfgram Memorial Library website: http://www2.widener.edu/Wolf gram-Memorial Library/webevaluation/we beval.htm

Bibliographic references Harvard format APA style. (2011). Retrieved from University of Portsmouth website: http://www.port.ac. uk/library/guides/filetodownload,137568,e n.pdf 